\title{
Nucleation time of gall bladder bile in gall stone patients: influence of bile acid treatment
}

\author{
S Sahlin, J Ahlberg, B Angelin, E Reihnér, K Einarsson
}

\begin{abstract}
The time required for precipitation of cholesterol crystals (nucleation time, NT) was determined and related to the cholesterol saturation in gall bladder bile of gall stone free subjects $(n=11)$, patients with pigment stones $(n=3)$, and patients with cholesterol gall stones $(\mathbf{n}=30)$ undergoing cholecystectomy. Seven of the gall stone patients had been treated with chenodeoxycholic acid (CDCA) and nine with ursodeoxycholic acid (UDCA), $15 \mathrm{mg} / \mathrm{kg} /$ day for three weeks before operation. NT was longer in gall stone free subjects (mean, 20 days), patients with pigment stones (14 days) and patients treated with CDCA ( 24 days) and UDCA (17 days) compared with untreated patients with cholesterol gall stones ( 1.5 days). In spite of low cholesterol saturation and prolonged NT, and in contrast to those treated with CDCA, four of the nine patients treated with UDCA had cholesterol crystals in their bile. These observations give further support to the concept that the mechanism for inducing gall stone dissolution may be different for CDCA and UDCA.
\end{abstract}

Bile, supersaturated with cholesterol, is a prerequisite but not the only requirement for gall stone formation in humans. ' In order to explain why gall stone free subjects also frequently have an excess of cholesterol in their bile, ${ }^{1-3}$ Holan et $a l^{4}$ have introduced the concept of nucleation time (NT) - defined as the time required for cholesterol precipitation in vitro as monohydrated cholesterol crystals in centrifuged and particle-free bile (NT could also be called the cholesterol microcrystal appearance/detection time). NT is the only parameter which discriminates cholesterol stone bile from normal bile with the same cholesterol saturation index. The short NT in cholesterol gall stone patients is considered to be due to an imbalance between nucleating and antinucleating agent(s). ${ }^{5}$

In 1972 it was shown that treatment with

Department of Surgery Karolinska Institute, Danderyd Hospital

S Sahlin

J Ahlberg

Departments of Medicine and Surgery, Karolinska Institute at Huddinge University Hospital, Huddinge, Sweden

B Angelin

E Reihnér

K Einarsson

Correspondence to:

Dr Staffan Sahlin,

Department of Surgery

Department of Surgery,

Danderyd Hospital,
Danderyd, Sweden.

Accepted for publication

21 January 1991 of its pathogenesis is limited. The enhanced cholesterol saturation of bile appears to be due mainly to an absolute increase in the secretion rate of cholesterol from the liver, whereas the secretion rates of bile acids and phospholipids are normal. ${ }^{12}$

The aims of this study were twofold: to determine the NT of gall bladder bile in Swedish gall stone patients and gall stone free subjects, and to study the influence of treatment with CDCA and UDCA in doses known to make bile unsaturated with cholesterol in gall stone patients.

\section{Materials and methods}

\section{PATIENTS}

Forty four patients undergoing elective cholecystectomy were studied: 11 without and 33 with gall stones, three of whom had pigment stones (Table I). The gall stone free patients were cholecystectomised because of suspected adenomyomas or polyps of the gall bladder. Seven of the patients with cholesterol gall stones were treated with CDCA and nine with UDCA before operation. All patients were non-obese (relative body weight less than 125\%) and normolipidaemic, and none had any clinical or laboratory evidence of diabetes, diseases affecting liver or kidney function, or alcohol abuse. Preoperative cholecystography had shown a well functioning gall bladder in all cases. Also indicative of a functioning gall bladder was the presence of dark concentrated bile in the gall bladder and no evidence of impacted stones in the neck of the cystic duct at operation. Informed consent was obtained from each patient before the study, and the protocols were approved by the Ethics Committee at Karolinska Institute, Stockholm.

\section{EXPERIMENTAL PROCEDURE}

CDCA and UDCA were administered in a daily dose of $15 \mathrm{mg} / \mathrm{kg}$ body weight for three weeks before operation. The capsules were taken twice daily and the last capsules in the evening before the day of operation. The medication was well tolerated; most of the subjects treated with CDCA noted softer stools, and two developed occasional diarrhoea. Liver function tests were normal during the medication. All operations were performed between 8 and 10 am after an overnight fast. After opening of the abdomen, the gall bladder was completely emptied of bile using a sterile needle and syringe to avoid possible stratification of bile. ${ }^{13} \mathrm{~A}$ routine cholecystectomy was then performed. The gall stones were classified as cholesterol or pigment stones by analysis in the laboratory. ${ }^{14}$ 
TABLE I Basal data of the patients. Values are mean (SEM)

\begin{tabular}{|c|c|c|c|c|c|c|c|}
\hline \multirow[b]{2}{*}{ Patient group } & \multirow[b]{2}{*}{ No } & \multirow{2}{*}{$\begin{array}{l}\text { Sex } \\
M / F\end{array}$} & \multirow{2}{*}{$\begin{array}{l}\text { Age } \\
\text { (years) }\end{array}$} & \multicolumn{2}{|c|}{ Body weight } & \multirow{2}{*}{$\begin{array}{l}\text { Plasma } \\
\text { cholesterol } \\
(\text { mmolll })\end{array}$} & \multirow{2}{*}{$\begin{array}{l}\text { Plasma } \\
\text { triglycerides } \\
\text { (mmol/l) }\end{array}$} \\
\hline & & & & kg & $\%^{\star}$ & & \\
\hline \multicolumn{8}{|c|}{ Cholesterol gall stone } \\
\hline Untreated & 14 & $4 / 10$ & $49(4)$ & $67(3)$ & $98(4)$ & $5 \cdot 2(0 \cdot 5)$ & $1 \cdot 1(0 \cdot 2)$ \\
\hline UDCA & 9 & $2 / 7$ & $47(4)$ & $69(3)$ & $98(3)$ & $5 \cdot 2(0 \cdot 2)$ & $1 \cdot 1(0 \cdot 1)$ \\
\hline CDCA & 7 & $1 / 6$ & $42(3)$ & $74(5)$ & $105(6)$ & $5 \cdot 0(0 \cdot 2)$ & $1 \cdot 0(0 \cdot 1)$ \\
\hline Gall stone free & 11 & $3 / 8$ & $48(4)$ & $68(4)$ & $95(4)$ & $6 \cdot 2(0 \cdot 4)$ & $1 \cdot 1(0 \cdot 2)$ \\
\hline Pigment gall stone & 3 & $1 / 2$ & $55(14)$ & $67(6)$ & $89(11)$. & $5 \cdot 1(0 \cdot 6)$ & $1 \cdot 0(0 \cdot 1)$ \\
\hline
\end{tabular}

\section{MATERIALS}

CDCA (Chenofalk) and UDCA (Ursofalk) were administered in $250 \mathrm{mg}$ capsules purchased from Dr Falk Pharma, while $3 \alpha$-hydroxysteroid dehydrogenase (Sterognost) and cholesterol oxidase (Nyco-test cholesterol) were purchased from Nyegaard A/S.

\section{BILE LIPID ANALYSIS}

For the determination of cholesterol and phospholipids, a portion of the bile samples obtained was immediately extracted with 20 volumes of chloroform-methanol, 2:1 (v/v). Cholesterol was determined by an enzymatic method ${ }^{16}$ and phospholipids by the method of Rouser et al. ${ }^{17}$ The total bile acid concentration in another aliquot of the bile sample was determined using the $3 \alpha$-hydroxysteroid dehydrogenase assay. ${ }^{18}$ Cholesterol saturation was calculated as a percentage of the predicted cholesterol solubility at the respective biliary lipid concentration and composition as described by Carey. ${ }^{19}$ The calculation of cholesterol saturation in patients treated with UDCA was performed both with and without the correction factor for UDCA-rich bile described by Carey. ${ }^{19}$

\section{BILE ACID ANALYSIS}

Aliquots of bile were hydrolysed in $1 \mathrm{M}$ potassium hydroxide at $110^{\circ} \mathrm{C}$ for 12 hours. The deconjugated bile acids were extracted with ethyl ether after acidification to $\mathrm{pH} 1$ with hydrochloric acid. After preparation of the methyl trimethylsilyl ethers, the bile acids were further analysed by gas-liquid chromatography using $1 \% \mathrm{Hi}$-Eff BP8 as the stationary phase. A PYE Unicam chromatograph equipped with a $1.5 \mathrm{~m} \times 4 \mathrm{~mm}(\mathrm{OD})$ column was used. ${ }^{20}$

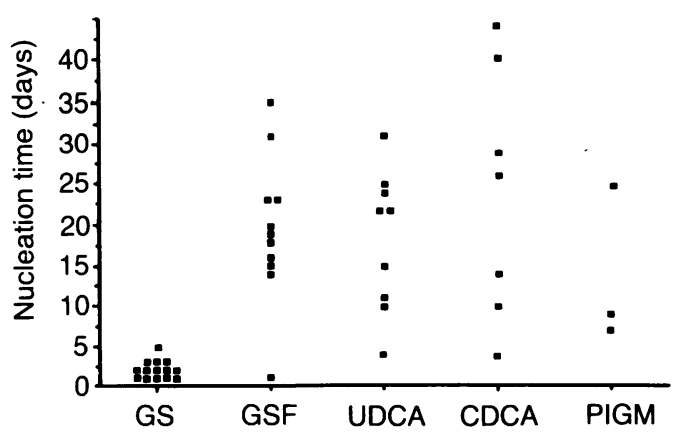

Figure 1: Nucleation time of gall bladder bile of untreated cholesterol gall stone patients $(G S)$, gall stone free subjects $(G S F)$, cholesterol gall stone patients treated with ursodeoxycholic acid (UDCA) or chenodeoxycholic acid (CDCA) and pigment gall stone patients (PIGM).

\section{ANALYSIS OF CHOLESTEROL CRYSTALS AND NT}

Bile was transported and stored at $37^{\circ} \mathrm{C}$. All bile samples were examined for typical rhomboid monohydrate cholesterol crystals by polarising light microscopy on prewarmed slides. The uncentrifuged bile was inspected immediately after operation and after one day.

NT was determined by the method of Holan et $\mathrm{al}^{+}$with minor modifications. After centrifugation of about $6 \mathrm{ml}$ bile at $100000 \mathrm{~g}$ for 2 hours, $3 \mathrm{ml}$ from the middle phase were transferred into a sterile glass vial and sealed with a cap equipped with a permeable silicon membrane. The vial was stored in darkness in an incubator at $37^{\circ} \mathrm{C}$. About $3 \mu \mathrm{l}$ from the top, middle, and bottom portion were aspirated each day, mixed and placed on a prewarmed slide and viewed thoroughly in polarising light microscope. NT was defined as the number of days until typical rhomboid monohydrate cholesterol crystals appeared.

\section{STATISTICAL ANALYSIS}

Data are presented as means with standard error of the mean (SEM). The statistical significance of difference was evaluated by the Mann-Whitney $\mathrm{U}$ test. Correlations between parameters were tested by estimating the Spearman's rank correlation coefficient, $r$.

\section{Results}

BILIARY MICROSCOPY AND CHOLESTEROL NT

At the time of surgery, cholesterol crystals were detected in gall bladder bile of 11 out of the 14

TABLE II Cholesterol crystals, nucleation time (NT), lipid composition, lipid concentration and cholesterol saturation of gall bladder bile. Values are mean (SEM)

\begin{tabular}{|c|c|c|c|c|c|c|c|c|}
\hline Patient group & No & $\begin{array}{l}\text { Patients with } \\
\text { cholesterol } \\
\text { crystals }\end{array}$ & $\begin{array}{l}N T \\
(\text { days })\end{array}$ & $\begin{array}{l}\text { Cholesterol } \\
(\mathrm{mol} \%)\end{array}$ & $\begin{array}{l}\text { Bile acids } \\
(\mathrm{mol} \%)\end{array}$ & $\begin{array}{l}\text { Phospholipids } \\
(\text { mol\%) }\end{array}$ & $\begin{array}{l}\text { Lipid } \\
\text { concentration } \\
(\mathrm{g} / d \mathrm{~d})\end{array}$ & $\begin{array}{l}\text { Cholesterol } \\
\text { saturation } \\
(\%)\end{array}$ \\
\hline \multicolumn{9}{|c|}{ Cholesterol gall stone } \\
\hline Untreated & 14 & 11 & $1.5(0.3)$ & $7 \cdot 6(0 \cdot 7)$ & $70 \cdot 0(1 \cdot 6)$ & $22 \cdot 3(1 \cdot 1)$ & $9 \cdot 6(1 \cdot 3)$ & $111(10)$ \\
\hline UDCA treated & 9 & 4 & $17 \cdot 0(3.0)$ & $3.5(0.6) \ddagger$ & $72 \cdot 4(1 \cdot 7)$ & $24 \cdot 0(1 \cdot 3)$ & $8 \cdot 2(1 \cdot 4)$ & $50(7) \ddagger$ \\
\hline CDCA treated & 7 & it & $23.9(5.7) \delta$ & $4 \cdot 7(0.5) \dagger$ & $71 \cdot 1(1 \cdot 3)$ & $24 \cdot 3(1 \cdot 2)$ & $11 \cdot 4(1 \cdot 4)$ & $63(7) \dagger$ \\
\hline Gall stone free & 11 & $1 \neq$ & $19 \cdot 5(2 \cdot 7) \S$ & $5.6(0.6)$ & $70 \cdot 6(1.4)$ & $23.7(1.4)$ & $12.0(1.6)$ & $79(10)^{\star}$ \\
\hline Pigment stone & 3 & 0 & $13.7(5.7) t$ & $6.0(1.5)$ & $70 \cdot 1(3 \cdot 5)$ & $24 \cdot 0(2 \cdot 0)$ & $8 \cdot 3(2 \cdot 3)$ & 84 (19) \\
\hline
\end{tabular}




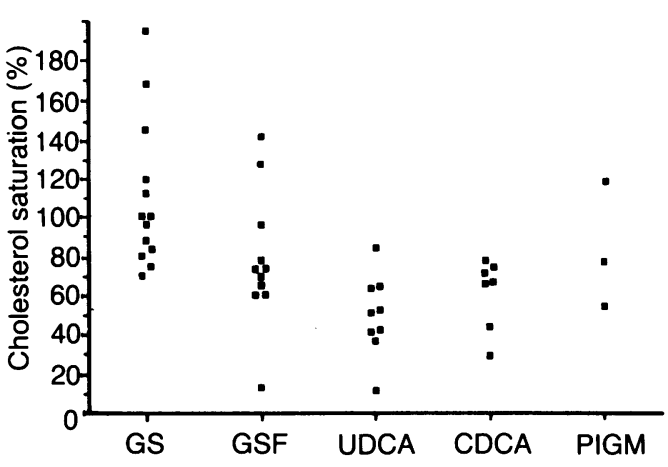

Figure 2: Cholesterol saturation in gall bladder bile of untreated cholesterol gall stone patients $(G S)$, gall stone free subjects $(G S F)$, cholesterol gall stone patients treated with ursodeoxycholic acid (UDCA) or chenodeoxycholic acid (CDCA) and pigment gall stone patients (PIGM).

patients with untreated cholesterol gall stones (79\%), 1/11 gall stone free subjects, 4/9 UDCA treated and 1/7 CDCA treated patients, and in none of the three patients with pigment stones (Table II). The difference between the untreated cholesterol gall stone group and the gall stone free group was significant $(\mathrm{p}<0.001)$.

NT was significantly shorter in the gall stone group compared with the gall stone free group $(1.5(0.3)$ days $v 20(3)$ days, $\mathrm{p}<0.0001)$ (Table II). Only one gall stone free subject had a short NT (Fig 1). Treatment with CDCA and UDCA prolonged NT to 24 (6) days and 17 (3) days (Table II, Fig 1). The NT of the three patients with pigment stones averaged 14 days.

\section{BILIARY LIPID COMPOSITION}

The results of biliary lipid analysis are shown in Table II. The cholesterol saturation of gall bladder bile was lower in the gall stone free group compared with the untreated cholesterol gall stone group (79 (10) v $111(10) \%, \mathrm{p}<0.05)$, although there was a certain overlap (Fig 2). Gall bladder bile was unsaturated in all the patients treated with CDCA (63 (7)\%) and UDCA (50 (2)\% or 67 (9)\% with Carey's correction factor) (Fig 2, Table II).

\section{BILE ACID COMPOSITION}

Analysis of the individual bile acids confirmed good patient compliance in the treatment groups. Thus, CDCA constituted 82 (1)\% and UDCA 45 (3)\% in the groups treated with CDCA and UDCA, respectively (Table III).

No correlations were found between the NT and the biliary cholesterol saturation or lipid composition in any of the different patient groups.

TABLE III Bile acid composition in gall bladder bile. Values as mean (SEM)

\begin{tabular}{|c|c|c|c|c|c|}
\hline Patient groups & $\begin{array}{l}\text { Cholic } \\
\text { acid } \\
(\%)\end{array}$ & $\begin{array}{l}\text { Deoxhcholic } \\
\text { acid } \\
(\%)\end{array}$ & $\begin{array}{l}\text { Chenodeoxycholic } \\
\text { acid } \\
(\%)\end{array}$ & $\begin{array}{l}\text { Ursodeoxycholic } \\
\text { acid } \\
(\%)\end{array}$ & $\begin{array}{l}\text { Lithocholic } \\
\text { acid } \\
(\%)\end{array}$ \\
\hline $\begin{array}{l}\text { Cholesterol gall stone } \\
\text { Untreated } \\
\text { CDCA treated } \\
\text { UDCA treated } \\
\text { Gall stone free } \\
\text { Pigment gall stone }\end{array}$ & $\begin{array}{l}49(2) \\
13(1) \ddagger \\
23(3) \oint \\
41(4)^{\star} \\
40(1)\end{array}$ & $\begin{array}{l}18(2) \\
0 \cdot 1(0 \cdot 1) \ddagger \\
13(2) \\
21(4) \\
29(6)\end{array}$ & $\begin{array}{l}32(2) \\
82(1) \ddagger \\
15(1) \uparrow \\
36(5) \\
29(5)\end{array}$ & $\begin{array}{c}1(0) \\
3(1) \dagger \\
45(3) \S \\
2(1) \\
1(1)\end{array}$ & $\begin{array}{l}0 \cdot 4(0 \cdot 2) \\
2(1)^{\star} \\
4(1) \\
1(1) \\
0 \cdot 1(0 \cdot 1)\end{array}$ \\
\hline
\end{tabular}

Significantly different from untreated gall stone patients: ${ }^{\star} \mathrm{p}<0.05 ; \mathrm{tp}<0.01 ; \neq \mathrm{p}<0.001 ; \oint \mathrm{p}<0.0001$.

\section{Discussion}

In the present study, we found a short NT (mean of 1.5 days) in gall bladder bile of patients with untreated cholesterol gall stones and all but one of gall stone free subjects had a long NT (mean of 20 days). In agreement with Holan $e t a l^{+}$we found that NT provided a better discrimination between patients with and without cholesterol gall stones than did cholesterol saturation. We could not find any profound influence on NT by cholesterol concentration, cholesterol saturation, or total lipid concentration of gall bladder bile in gall stone patients or in gall stone free subjects. Tazuma et $a l^{11}$ reported recently that the NT in gall stone free subjects was seven to eight times longer than that in cholesterol gall stone patients, although the gall stone free subjects in that study also had saturated bile (mean cholesterol saturation, $112 \%$ ) It is thus evident that not only cholesterol saturation but also other factors are of importance for the nucleation process.

Another important finding of the present study was that the treatment of gall stone patients with a relatively high dose of UDCA, making gall bladder bile unsaturated with cholesterol, prolonged the NT to about the same level as that seen in gall stone free subjects. This confirms and extends the observation of two recent studies. ${ }^{11}$ Thus, Tazuma et al" found a prolonged NT in gall stone patients who had been treated with UDCA (300-600 mg/day) for three months in an unsuccessful attempt to dissolve their gall stones. The cholesterol saturation of gall bladder bile was not significantly lowered by the treatment and bile was thus still saturated with cholesterol. Because of the relatively low dose of UDCA used in that study, the mean percentage of UDCA obtained was only $22 \%$ compared to $45 \%$ in our study. Jüngst et al ${ }^{10}$ also found a prolonged NT ( 12 days) in gall stone patients treated with a low dose of UDCA (250 mg) for a short period of time, 6-10 days. The biliary cholesterol saturation in that study averaged $94 \%$. Thus we can conclude that both low and high dose UDCA prolongs NT in gall stone patients, and that this occurs whether gall bladder bile becomes unsaturated or not.

A major new finding of the present study was that treatment of gall stone patients with CDCA prolonged the NT to about 24 days, meaning that the NT was about 15 times longer than that seen in untreated gall stone patients. Bile from CDCA treated patients was unsaturated with cholesterol, and only one sample contained cholesterol crystals. In a previous study from our laboratory, cholesterol crystals were not observed in bile samples from seven CDCA treated patients. ${ }^{21}$

The reason for the prolonged NT during treatment with UDCA and CDCA is not evident. As mentioned above, the degree of cholesterol saturation does not seem to be of major importance, particularly not in UDCA-rich bile. According to current opinion, the short NT in gall stone patients is due to an imbalance between nucleating agent(s) and antinucleating or stabilising agent(s). ${ }^{52}$ So far, these factors have not been characterised, but circumstantial evidence suggests that they may be proteins. Tazuma et $a l^{11}$ have suggested that changes in the biliary 
concentrations of apolipoprotein A-I may play a role in the nucleation process during UDCA treatment. From results of animal experiments, it has been suggested that mucin may act as a nucleation promoting factor..$^{2324} \mathrm{We}$, as well as other authors, have shown that gall stone patients have a higher mucin content in the gall bladder bile than gall stone free subjects. ${ }^{25-28}$ However, treatment of gall stone patients with CDCA or UDCA did not significantly affect the mucin concentration. ${ }^{25}$

In spite of a prolonged NT, four of our nine UDCA treated patients had cholesterol crystals in their gall bladder bile. This result is in agreement with a previous study from our laboratory, in which $40 \%$ of the UDCA treated patients, but none of the CDCA treated, had cholesterol crystals. ${ }^{21}$ Jüngst $e t a l^{10}$ reported that $70 \%$ of their UDCA treated patients had cholesterol crystals. The reason why bile from UDCA treated patients contains crystals more frequently than bile from CDCA treated patients is not clear. It may be due to different dissolving mechanisms between the two bile acids. UDCA is more hydrophilic and may dissolve cholesterol mainly in the form of liquid crystals or vesicles, whereas CDCA dissolves cholesterol in micelles. ${ }^{2930}$ Whether this is also true in gall bladder bile of patients treated with UDCA, whose biliary bile acids become enriched only 40 to $50 \%$ in UDCA, can only be speculated on. It has been suggested that cholesterol crystals are formed from cholesterol in vesicles and not in micelles. ${ }^{31}$ When exposed to a nucleating factor (or not exposed to an antinucleating factor), the vesicles may precipitate as solid crystals. Another possibility is that monohydrate cholesterol crystals are discharged directly from the surface of the gall stones and do not represent de novo nucleation and crystal growth in the bile. If so, the crystals may not be dissolved in UDCA treated patients, but dissolved in CDCA treated patients.

In conclusion, we have shown that both CDCA and UDCA treatment prolongs NT. The NT was about 10 to 15 times longer in gall stone free subjects and gall stone patients treated with bile acids compared to untreated cholesterol gall stone patients. We also found that in several of the bile samples from UDCA treated patients, cholesterol crystals appeared in spite of a very low cholesterol saturation, which may indicate different modes of action whereby UDCA and CDCA may induce gall stone dissolution.

The skilful technical assistance of Ms Lisbet Benthin, Ms Danuta Cosliani, and Ms Ingela Svensson is gratefully acknowledged. We wish to express our gratitude to Ms Eva Lind, Ms Inga-Lill Olsson, and Ms Catrine Olsson for secretarial assistance. This investigation was supported by grants from the Swedish Medical investigation was supported by grants from the Swedish Medical Research Council (projecticine (No 671).
of Medicis

1 Hofmann AF. Pathogenesis of cholesterol gall stones. $\mathcal{f}$ Clin Gastroenterol 1988; 10 (suppl 2): S1-S11.
2 Holzbach RT, Marsh M, Olszewski M, Holan K. Cholesterol solubility in bile. Evidence that supersaturated bile is frequent in healthy man. $\mathcal{F}$ Clin Invest 1973; 52: 1467-79.

3 Ahlberg J, Angelin B, Einarsson K, Hellström K, Leijd B. Biliary lipid composition in normo- and hyperlipoproteinemia. Gastroenterology 1980; 79: 90-4.

4 Holan KR, Holzbach RT, Hermann RE, Cooperman AM, Claffey WJ. Nucleating time: a key factor in pathogenesis of cholesterol gall stone disease. Gastroenterology 1979; 77: 611-7.

5 Holzbach RT. Recent progress in understanding cholesterol crystal nucleation as a precursor to human gall stone formation. Hepatology 1986; 6: 1403-6.

6 Danzinger RG, Hofmann AF, Schoenfield LJ, Thistle JL. Dissolution of cholesterol gall stones by chenodeoxycholic acid. N Engl f Med 1972; 286: 1-8.

7 Bell GD, Whitney B, Dowling RH. Gall stone dissolution in man using chenodeoxycholic acid. Lancet 1972; ii: 1213-6.

8 Nakano Y, Nakano K. Some cases of gall stones dissolved by bile acid preparations. $\mathcal{F}$ Natl Council Communal Hospitals 1973; 70: 25-32.

9 Tint GS, Salen G, Shefer S. Effect of ursodeoxycholic acid and chenodeoxycholic acid on cholesterol and bile acid metabolism. Gastroenterology 1986; 91: 1007-18.

10 Jüngst $D$, Brenner G, Pratschke E, Paumgartner G. Lowdose ursodeoxycholic acid prolongs cholesterol nucleation time in gallbladder bile of patients with cholesterol gallstones. F Hepatol 1989; 8: 1-6.

11 Tazuma S, Sasaki H, Mizuno S, Sagawa H, Hashiba S, Horiuchi I, et al. Effect of ursodeoxychoic acid administration on nucleation time in human gallbladder bile. Gastroenterology 1989; 97: 173-8.

12 Nilsell K, Angelin B, Liljeqvist L, Einarsson K. Biliary lipid output and bile acid kinetics in cholesterol gallstone disease: evidence for an increased hepatic secretion of cholesterol in Swedish patients. Gastroenterology 1985; 89: 287-93.

13 Tera H. Stratification of human gallbladder bile in vivo. Acta Chir Scand 1960; Suppl 256: 4-65.

14 Trotman BW, Ostrow JD, Soloway RD. Pigment $v$ cholesterol cholelithiasis: comparison of stone and bile composition. Am $\mathcal{f}$ Dig Dis 1974; 19: 585-90.

15 Whiting MJ, Down RH, Watts JMcK. Biliary crystals and granules, the cholesterol saturation index, and the predicgranules, the cholesterol saturation index, and the predic-
tion of gallstone type. Surgical Gastroenterology 1982; 1: tion of

16 Roda A, Festi D, Sama C, Mazzeli G, Aldini R, Roda E, et al. Enzymatic determination of cholesterol in bile. Clin Chim Acta 1975; 64: 337-41

17 Rouser G, Sidney F, Akira Y. Two dimensional thin-layer chromatography separation of polar lipids and determination of phospholipids by phosphorus analysis of spots. Lipids 1975; 5: 494-6.

18 Fausa O, Skålhegg BA. Quantitative determination of bile acids and their conjugates using thin-layer chromatography and purified $3 \alpha$-hydroxysteroid dehydrogenase. Scand and purified 3 $\alpha$-hydroxy

19 Carey MC. Critical tables for calculating the cholesterol saturation of native bile. $\mathcal{F}$ Lipid Res 1978; 19:945-55.

20 Angelin B, Einarsson K, Leijd B. Biliary lipid composition during treatment with different hypolipidaemic drugs. Eur f Clin Invest 1979; 9: 185-90.

21 Sahlin S, Ahlberg J, Angelin B, Ewerth S, Nilsell K, Reihnér $\mathrm{E}$, et al. Occurrence of cholesterol monohydrate crystals in gallbladder and hepatic bile in man: influence of bile acid treatment. Eur f Clin Invest 1988; 18: 386-90.

22 Groen AK, Drapers JAG, Tytgat GNJ. Cholesterol nucleation and gallstone formation. F Hepatol 1988; 6: 383-7.

23 Wahlin T. Effects of lithogenic diet on mouse gallbladder epithelium. Virchows Arch [B] 1976; 22: 273-86.

24 Lee SP, LaMont JT, Carey MC. Role of gallbladder mucus hypersecretion in the evaluation of cholesterol gallstones. hypersecretion in the evaluation

25 Sahlin S, Danielsson Å, Angelin B, Reihnér E, Henriksson R, Einarsson $\mathrm{K}$. Mucin in gall bladder bile of gall stone patients: influence of treatment with chenodeoxycholic acid and ursodeoxycholic acid. Gut 1988; 29: 1506-10.

26 Bouchier IAD, Cooperband SR, El Kodsi BM. Mucous substances and viscosity of normal and pathological human bile. Gastroenterology 1965; 49: 343-53.

27 Lee SP, Lim TH, Scott AJ. Carbohydrate moieties of glycoproteins in human hepatic and gallbladder bile, gallbladder proteins in human hepatic an gall stones. Clin Sci 1979; 56: 533-8.

28 Mingrone G, Greco AV, Finotti E, Passi S. Free fatty acids: a stimulus for mucin hypersecretion in cholesterol gallstone stimulus for mucin hypersecretion in choles
biles. Biochim Biophys Acta 1988; 958: 52-9.

29 Corrigan OI, Su CC, Higuchi WI, Hofmann AF. Mesophase formation during cholesterol dissolution in ursodeoxycholiclecithin solutions: new mechanism for gallstone dissolution in humans. F Pharm Sci 1980; 69: 869-70

30 Salvioli G, Igimi M, Carey MC. Cholesterol gallstone dissolution in bile. Dissolution kinetics of crystalline cholestero monohydrate by conjugated chenodeoxycholate-lecithin and conjugated ursodeoxycholate-lecithin mixtures: dissimilar phase equilibria and dissolution mechanisms. $\mathcal{F}$ Lipid Res 1983; 24: 701-20.

31 Halpern Z, Dudley MA, Kibe A, Lynn MP, Breuer AC, Holzbach RT. Rapid vesicle formation and aggregation in abnormal human bile. A time-lapse video-enhanced contrast microscopic study. Gastroenterology 1986; 90: 875-85. 